\title{
A Campanha Internacional de Ação pela Despatologização das Identidades Trans: entrevista com o ativista Amets Suess
}

\author{
Berenice Bento \\ Universidade Federal do Rio Grande do Norte
}

\begin{abstract}
Atualmente mais de trezentos grupos espalhados por cidades do mundo inteiro estão mobilizados pelo fim da patologização do gênero, exigindo a retirada das categorias de "disforia de gênero"/"transtornos de identidade de gênero" do Manual Diagnóstico e Estatístico de Transtornos Mentais (DSM), da Associação Psiquiátrica Norte-Americana (APA), e do Código Internacional de Doenças. ${ }^{2}$ Entre as milhares de pessoas que hoje se somam na Campanha Internacional de Ação pela Despatologização das Identidades Trans, o sociólogo Amets Suess certamente pode ser apontado como um de seus mais expressivos teóricos e ativistas.

Membro ativo na Rede Internacional pela Despatologização Trans e do grupo Conjuntos Difusos, sediado em Granada, Espanha, Suess é um dos autores colaboradores do livro El género desordenado: críticas en torno a la patologización de la transexualidad, publicado em 2010 pela editora Egales (Madri) e organizado por Miquel Missé e Gerard CollPlanas, nomes conhecidos no ativismo trans.

Licenciado em Sociologia e doutorando em Antropologia Social na Universidade de Granada, Suess publicou diversos artigos acadêmicos sobre gênero, sexualidade e questões de saúde, entre os quais destacamos o recente "Despatologización trans y práctica arteterapéutica", editado pela revista espanhola Arte y Politicas de Identidad. ${ }^{2}$
\end{abstract}

Copyright $\odot 2012$ by Revista Estudos Feministas

'Ver artigo de Bento e Pelúcio neste volume.

${ }^{2}$ Disponível em: <http://www.arteypoliticasdeidentidad.org >. 
Contatado pela professora Berenice Bento (UFRN), Suess concedeu a entrevista abaixo, na qual fala das principais demandas da campanha Stop Trans Pathologization, elenca as principais ações já realizadas e fala dos desafios a serem enfrentados. Entre esses, o de garantir direitos já conquistados na área da saúde sem as implicações patologizantes que hoje pesam sobre as pessoas transexuais. A entrevista de Suess aclara pontos, convoca a reflexão e contribui para a divulgação dessa imprescindível campanha. 
Berenice Bento: ¿Cómo ha empezado la Campaña STP 2012? Amets Suess: En su inicio, STP 2012, Campaña Internacional Stop Trans Pathologization, surge de la convocatoria de redes activistas trans procedentes, en su mayoría, del contexto español, logrando una difusión internacional y participación de grupos activistas en diferentes partes del mundo. Desde el año 2007, se convocan cada mes de octubre movilizaciones por la despatologización trans. Mientras en 2007 y 2008 se celebraron demonstraciones coordinadas en diferentes ciudades europeas, a partir de 2009 se realizan convocatorias anuales de carácter internacional, bajo el nombre STP 2012, Campaña Internacional Stop Trans Pathologization. En Octubre de 2009, grupos activistas de 41 ciudades de diferentes regiones del mundo participaron en el Día Internacional de Acción por la Despatologización Trans. En Octubre de 2010, el número de ciudades en las que se realizaron acciones por la despatologización trans ascendió a 61 , y en Octubre de 201 1, a 70 . Además, a fecha de febrero de 2012, más de 300 grupos, redes y organizaciones de África, América Latina, Asia, Europa, Norteamérica y Oceanía han declarado su adhesión a la Campaña Internacional STP 2012.

BB: ¿Cuáles son los principales retos de la Campaña?

AS: Las principales demandas de la Campaña STP 2012 son la retirada de las categorías relacionadas con los procesos de transición en el género de los manuales diagnósticos DSM y $\mathrm{CIE}$, así como la garantía de los derechos sanitarios de las personas trans, incluyendo la garantía de cobertura pública de una atención sanitaria trans-específica de la más alta calidad posible y el cambio del modelo actual de evaluación por un enfoque basado en la decisión informada.

Como uno de los principales retos del activismo por la despatologización trans se puede identificar el cambio en la conceptualización de la relación entre despatologización y derecho de acceso a una atención sanitaria trans-específica de calidad y públicamente cubierta. En este sentido, no concebimos la demanda de despatologización y la demanda de cobertura pública como dos objetivos contrapuestos y excluyentes, sino como dos derechos humanos fundamentales. Para lograr el objetivo de una despatologización de las expresiones e identidades trans al mismo tiempo que facilitar la garantía del derecho de un acceso públicamente cubierto a los tratamientos trans-específicos, STP 2012 propone acompañar la retirada de la clasificación psiquiátrica actual por la introducción de una mención no patologizante de la atención sanitaria trans-específica en la CIE, como un proceso de atención no basado en una enfermedad. Al mismo tiempo, consideramos importante desarrollar nuevos modelos de salud trans basados en una perspectiva de despatologización, autonomía y decisión informada y demandar su introducción en las prestaciones sanitarias públicas. 
Como otro reto, se puede nombrar la complejidad de elaborar demandas y propuestas a nivel internacional, a la vez de tener en cuenta las necesidades específicas de las personas que transitan en el género en diferentes partes de mundo, en función del contexto cultural y características específicas de cada sistema sanitario.

BB: ¿La Campaña ha encontrado adhesiones del movimiento gay, lesbiano y feminista?

AS: Colectivos LGTB y feministas forman parte de la lista de grupos adheridos a la Campaña STP 2012. La defensa de los derechos de las personas LGTB, la lucha contra la homofobia y transfobia, la denuncia de procesos de patologización y violencia institucional, la reivindicación del derecho de autonomía sobre el propio cuerpo, así como la defensa de la diversidad corporal, sexual y de género se pueden nombrar como potenciales puntos de coincidencia entre el activismo LGTB, los movimientos feministas y el activismo por la despatologización trans.

BB: ¿Hay divergencia entre los activistas trans acerca de la despatologización?

AS: A lo largo de los últimos años, se puede observar un creciente consenso sobre la importancia de una de-psicopatologización de las expresiones, trayectorias e identidades de género trans y la demanda de una retirada de las categorías diagnósticas actuales del DSM y de la CIE, así como en relación a la necesidad de una abolición de los requisitos patologizantes presentes en las actuales leyes de reconocimiento de género.

Al mismo tiempo, se puede constatar una mayor variabilidad de opiniones y preferencias respecto a la elaboración de estrategias para garantizar el acceso a una atención sanitaria trans-específica públicamente cubierta. En este sentido, existen propuestas distintas para la introducción de una referencia nueva relacionada con la atención sanitaria trans-específica en la CIE que varían en función de las características del contexto sanitario y las posibilidades de una cobertura pública de la atención sanitaria trans-específica.

A lo largo de los últimos años, hemos tenido oportunidad de mantener un diálogo continuado con activistas trans de diferentes partes del mundo. Consideramos estos espacios de debate y reflexión sobre prioridades y estrategias compartidas y contextualmente específicas como un elemento fundamental para el activismo por la despatologización trans. 